Supporting Information

\title{
Theoretical insights into the selective oxidation of methane to methanol in copper-exchanged mordenite
}

Zhi-Jian Zhao, ${ }^{1,2}$ Ambarish Kulkarni, ${ }^{1}$ Laia Vilella, ${ }^{1,3}$ Jens K. Nørskov, ${ }^{1}$ Felix Studt ${ }^{\$ 1^{*}}$

[1] SUNCAT Center for Interface Science and Catalysis, SLAC National Accelerator Laboratory, 2575 Sand Hill Road, Menlo Park, CA 94025, United States and Department of Chemical Engineering, Stanford University, Stanford, CA 94305, United States.

[2] Key Laboratory for Green Chemical Technology of Ministry of Education, School of Chemical Engineering and Technology, Tianjin University; Collaborative Innovation Center of Chemical Science and Engineering, Tianjin 300072, China

[3] Departament de Química, Universitat Autònoma de Barcelona, Cerdanyola del Vallès, 08193, Barcelona, Spain.

$\S$ present address: Institute of Catalysis Research and Technology, Karlsruhe Institute of Technology, Hermann-von-Helmholtz-Platz 1, 76344 Eggenstein-Leopoldshafen, Germany

*Email: felix.studt@kit.edu

\section{Table of Contents}

1. Validation of BEEF-vdW functional

2. Details of Cu-MOR activated by N2O

3. Details of $\mathrm{CH}_{4}$ activation by $\mathrm{CuOCu}$

4. Details of $\mathrm{CH}_{4}$ activation by $\mathrm{CuOOCu}$

5. Details on the rate analysis

6. Stability of $\mathrm{CuOCu}$ cluster on different $\mathrm{T}$ site pairs

7. Steric hindrance of $\mathrm{CH}_{4}$ dissociation by T3-T3 site in 8MR 


\section{Validation of the BEEF-vdW functional}

Figure S1 shows a comparison of BEEF-vdW and HSE06 with HSE06/D3 for various oxo species bound to copper exchanged chabazite. Error bars obtained through the error estimation ensemble of the BEEF-vdW functional has been added to the BEEF-vdW data.
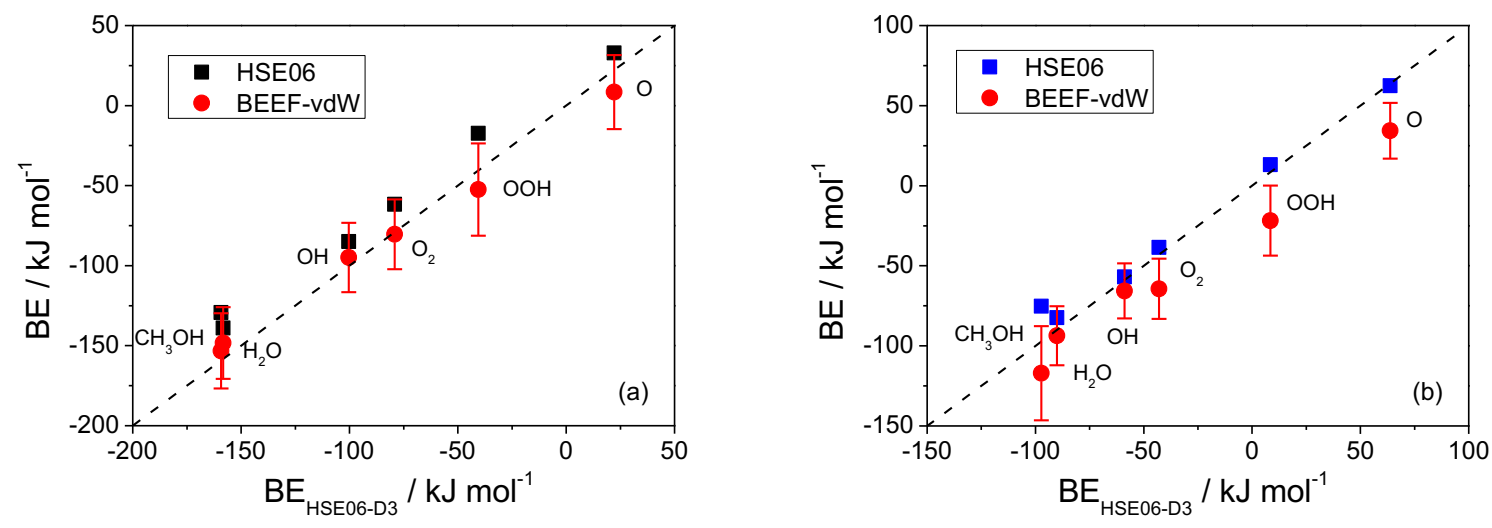

Figure S1 The adsorption energies of various intermediates in 8MR (left) and 6MR (right) of chabazite calculated using BEEF-vdW (red) and HSE06 (blue) compared to the HSE06/D3 values. The mean absolute deviation (MAD) for BEEF-vdW is $\sim 0.1$ and $0.2 \mathrm{eV}$ for $8 \mathrm{MR}$ and $6 \mathrm{MR}$, respectively.

\section{Details of Cu-MOR activated by $\mathrm{N}_{2} \mathrm{O}$}

In section 3.1, we considered the scenario with $\mathrm{N}_{2} \mathrm{O}$ as oxidant and two bare $\mathrm{Cu}$ atoms $\left(d_{\mathrm{Cu}-\mathrm{Cu}}=5.19 \AA\right)$ located on lattice oxygens of $\mathrm{Al}$, which are located in $\mathrm{T} 1$ and $\mathrm{T} 4$ sites. In the initial state, $\mathrm{N}_{2} \mathrm{O}$ binds to one of the $\mathrm{Cu}$ atoms, forming a $1.97 \AA \mathrm{Cu}-\mathrm{O}$ bond. In the transition state, the $\mathrm{O}$ atom in $\mathrm{N}_{2} \mathrm{O}$ start to approaching the second $\mathrm{Cu}$ atom, forming two systematic $\mathrm{Cu}-\mathrm{O}$ interactions with $2.12 \AA \mathrm{Cu}-\mathrm{O}$ distance. Accordingly, the di-Cu pair was attracted by the inserting $\mathrm{O}$ atom, and $\mathrm{Cu}-\mathrm{Cu}$ distance shrank to $3.86 \AA$. The $\mathrm{N}-\mathrm{O}$ bond in $\mathrm{N}_{2} \mathrm{O}$ is only slightly elongated from $1.06 \AA$ to $1.24 \AA$. In the final state, $\mu$-oxo dicupper $(\mathrm{Cu}-\mathrm{O}-\mathrm{Cu})$ was formed. The newly formed $\mathrm{Cu}-\mathrm{O}$ bond is $1.79 \AA$, and $\mathrm{Cu}-\mathrm{O}-\mathrm{Cu}$ angle is $146^{\circ}$ for the triplet state $[\mathrm{CuOCu}]^{2-}$. Although the singlet $[\mathrm{CuOCu}]^{2-}$ is $40 \mathrm{~kJ} \mathrm{~mol}^{-1}$ less stable than the triplet form, the $\mathrm{Cu}-\mathrm{O}-\mathrm{Cu}$ structure is quite similar between these two spin states, with bond length differ less than $0.01 \AA$.

In order to form di-oxygen active sites, an additional oxidation state is needed from $\mathrm{Cu}-\mathrm{O}-\mathrm{Cu}$. Interestingly, although this step results in direct insertion of a second $\mathrm{O}$ atom to 
form $\mu$-1,2-peroxo dicopper in the transition state, the inserting $\mathrm{O}$ atom only interact with

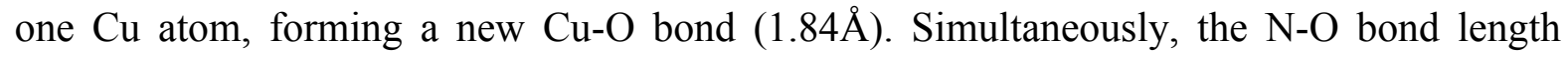
increases to $1.70 \AA$. Optimization along the imaginary frequency of this transition state structure do form $\mu$-1,2-peroxo dicopper, which is the final state of this reaction.

\section{Details of $\mathrm{CH}_{4}$ activation by $\mathrm{CuOCu}$}

The first elementary step is $\mathrm{C}-\mathrm{H}$ bond dissociation. In the transition state, one $\mathrm{H}$ atom approaches to the $\mathrm{O}$ in $\mathrm{Cu}-\mathrm{O}-\mathrm{Cu}$, forming a new $\mathrm{H}-\mathrm{O}$ bond at $1.19 \AA$. Accordingly, the $\mathrm{C}-\mathrm{H}$ bond elongated to $1.38 \AA \AA$. The free energy barrier of this step at $398 \mathrm{~K}$ is $99 \mathrm{~kJ} \mathrm{~mol}^{-1}$ reference to a gas phase $\mathrm{CH}_{4}$ and clean activated $\mathrm{Cu}-\mathrm{MOR}$. In the final state, $\mathrm{CH} 3$ forms a radical type structure which is stabilized by the newly formed $\mathrm{OH}$ group by $201 \mathrm{~kJ} \mathrm{~mol}^{-1}$, compared to the case where the $\mathrm{CH}_{3}$ radical is moved to a different place in $12 \mathrm{MR}$ of MOR away from the $\mathrm{OH}$ group. Charge difference analysis (Figure S1a) indicates that strong charge accumulation after moving $\mathrm{CH}_{3}$ and $\mathrm{OH}$ fragments into same unit cell. Indeed, the $\mathrm{C}$ $\mathrm{H}$ distance is still $2.19 \AA$ in the final state, in the range of a typical H-bond interaction.

Forming a real chemical bond can further stabilize the $\mathrm{CH}_{3}$ radical. The first choice we attempted is forming a $\mathrm{C}-\mathrm{O}$ bonding with $\mathrm{OH}$ group in $\mathrm{Cu}-\mathrm{OH}-\mathrm{Cu}$, which directly forms the final product $\mathrm{CH}_{3} \mathrm{OH}$. In the transition state, the $\mathrm{CH}_{3}$ radical start to approach the $\mathrm{O}$ atom, and the C-O distance shortens to $2.48 \AA$. Methanol was formed in the final state and only interacts with one $\mathrm{Cu}$, with $1.93 \AA \mathrm{Cu}-\mathrm{O}$ bond length.

Instead of directly forming $\mathrm{CH}_{3} \mathrm{OH}, \mathrm{CH}_{3}$ radical can also migrate to one of the $\mathrm{Cu}$ atom forming $\mathrm{Cu}-\mathrm{CH}_{3}$. In the transition state, the $\mathrm{CH}_{3}$ radial moves towards $\mathrm{Cu}$ atom, with $\mathrm{Cu}-\mathrm{C}$ distance to $3.25 \AA$. In the final state, a real $\mathrm{Cu}-\mathrm{C}$ bond was formed, with $1.99 \AA$ distance. In the last step, the $\mathrm{CH}_{3}$ further migrates towards the bridging $\mathrm{OH}$ group, forming a $\mathrm{Cu}-\mathrm{C}-\mathrm{O}$ three membered ring in the corresponding transition state, with $d_{\mathrm{Cu}-\mathrm{C}}=2.39 \AA$ and $d_{\mathrm{O}-\mathrm{C}}=$ 2.04 $\AA$. The final state of the reaction, adsorbed $\mathrm{CH}_{3} \mathrm{OH}$ on one $\mathrm{Cu}$, is the same as the one discussed in the previous paragraph.

(a)

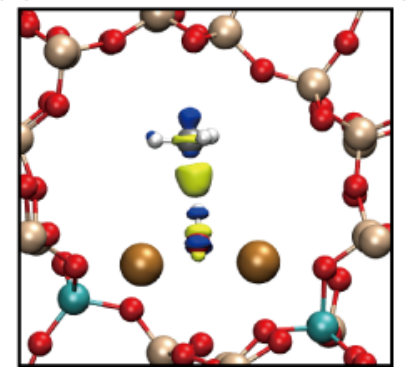

(b)

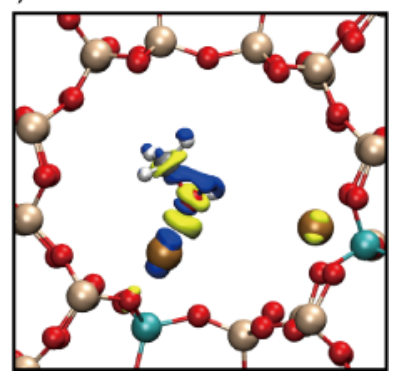


Figure S2 Charge difference map of (a) $\mathrm{OH}----\mathrm{CH}_{3}$ interaction and (b) $\mathrm{Cu}----\mathrm{CH} 3 \mathrm{OH}$ interaction. Yellow indicates charge accumulation and blue indicates charge depletion. Colors of atoms: Taupe - Si; Cyan - Al; Bronze - Cu; Red - O; While - H; Gray - C.

\section{Details of $\mathrm{CH}_{4}$ activation by $\mathrm{CuOOCu}$}

Similar as the reactions on $\mathrm{Cu}-\mathrm{O}-\mathrm{Cu}$, the $\mathrm{C}-\mathrm{H}$ activation step starts with one $\mathrm{H}$ atoms attracted by one $\mathrm{O}$ atom in the peroxo group. In the final state, the peroxo group accepts the dissecting $\mathrm{H}$ atom, leaving the $\mathrm{CH}_{3}$ radical in the $12 \mathrm{MR}$. The $\mathrm{C}-\mathrm{H}$ distance elongated to $2.08 \AA$, slightly shorter than the $\mathrm{Cu}-\mathrm{OH}-\mathrm{Cu}$ case. $\mathrm{The} \mathrm{CH}_{3}$ radical can be further stabilized by forming $\mathrm{Cu}-\mathrm{CH}_{3}$. However, the newly formed $\mathrm{Cu}-\mathrm{O}-\mathrm{OH}-\mathrm{Cu}$ is very unstable compared with $\mathrm{Cu}-\mathrm{OH}-\mathrm{Cu}$. This reaction step is endothermic by $\Delta \mathrm{G}_{398 \mathrm{~K}}=168 \mathrm{~kJ} \mathrm{~mol}^{-1}$, about $100 \mathrm{~kJ} \mathrm{~mol}^{-1}$ higher than the reaction energy of the same step catalyzed by $\mathrm{Cu}-\mathrm{O}-\mathrm{Cu}$.

However, even after forming $\mathrm{Cu}-\mathrm{CH}_{3}$, the free energy of the system is still $139 \mathrm{~kJ} \mathrm{~mol}^{-1}$ higher than the initial state of $\mathrm{C}-\mathrm{H}$ dissociation step, i.e. gas phase $\mathrm{CH}_{4}$ and $\mathrm{Cu}-\mathrm{MOR}$ with $\mathrm{Cu}-\mathrm{O}-\mathrm{O}-\mathrm{Cu}$. The only located thermodynamic more stable phase after $\mathrm{CH}_{4}$ dissociation is the one after $\mathrm{O}-\mathrm{O}$ bond breaking in the peroxo. The formed two fragments from $\mathrm{CH}_{4}$ dissociation were attached to these two $\mathrm{O}$ atoms separately, forming $\mathrm{OH}$ and $\mathrm{OCH}_{3}$. The reaction free energy, from gas phase $\mathrm{CH}_{4}$, is $-109 \mathrm{~kJ} \mathrm{~mol}^{-1}$. Although thermodynamically, the MOR with $\mathrm{Cu}-\mathrm{OH}$ and $\mathrm{Cu}-\mathrm{OCH}_{3}$ is more stable than $\mathrm{Cu}-\mathrm{O}-\mathrm{O}-\mathrm{Cu}$ and gas phase $\mathrm{CH}_{4}$ by more than $100 \mathrm{~kJ} \mathrm{~mol}^{-1}$, the attempts to locate the transition state which directly from intact $\mathrm{CH}_{4}$ is failed. All the reaction paths tend to converge to a scenario via an intermediate including $\mathrm{CH}_{3}$ radical. Thus, a higher barrier, more than $168 \mathrm{~kJ} \mathrm{~mol}^{-1}$, was expected for the dissociation of $\mathrm{CH}_{4}$ catalyzed by $\mathrm{Cu}-\mathrm{O}-\mathrm{O}-\mathrm{Cu}$ active center, which seems to be too high for a reaction occurring at $398 \mathrm{~K}$ as discussed in the main text.

\section{Details on the rate analysis}

By applying formula (1) and (2) in the main text, the forward rate of $\mathrm{CH}_{4}$ dissociation can be calculated. The calculated barrier for $\mathrm{CH}_{4}$ dissociation on $\mathrm{CuOCu}$ is $99 \mathrm{~kJ} \mathrm{~mol}^{-1}$ at $398 \mathrm{~K}$, and we get a rate of $0.79 \mathrm{~s}^{-1}$. The BEEF ensemble analysis estimate the error on this barrier is $\pm 18 \mathrm{~kJ} \mathrm{~mol}^{-1}$. By applying the upper $\left(117 \mathrm{~kJ} \mathrm{~mol}^{-1}\right)$ and lower $\left(81 \mathrm{~kJ} \mathrm{~mol}^{-1}\right)$ limits of barriers, we get two rates, 0.004 and $178.6 \mathrm{~s}^{-1}$, which are lower and upper bound of the DFT predicted forward rate on $\mathrm{CuOCu}$.

Similar analysis can be done for $\mathrm{CuOOCu}$ active site. Although we could not locate the 
transition state of C-H dissociation step, the lower bound of kinetic barrier can be estimated to be the thermodynamic barrier, which is the reaction energy of this step. With $\Delta G_{\text {Cuoocu }}^{a}$ being $168 \mathrm{~kJ} \mathrm{~mol}^{-1}$ barrier at $398 \mathrm{~K}$, we get a rate of $7.7 \times 10^{-10} \mathrm{~s}^{-1}$. The error bar on this reaction energy is $\pm 22 \mathrm{~kJ} \mathrm{~mol}^{-1}$. Thus, the fastest forward rate predicted by DFT is the one with the lower bound of the dissociation energy, $146 \mathrm{~kJ} \mathrm{~mol}^{-1}$, and the corresponding rate at $398 \mathrm{~K}$ is $6.7 \times 10^{-7} \mathrm{~s}^{-1}$, still four order of magnitude slower than the slowest rate predicted on $\mathrm{CuOCu}$.

\section{Stability of CuOCu cluster on different T site pairs}

The energy of $\mathrm{CuOCu}$ cluster on different $\mathrm{T}$ site pairs spread in a narrow range, except for the case on T1-T1 and T2-T2. The difference mainly due to the change of the coordination fashion between $\mathrm{Cu}$ and framework $\mathrm{O}$ atom. On T1-T1, both $\mathrm{Cu}$ atoms only single coordinated to the framework $\mathrm{O}$, while on $\mathrm{T} 2-\mathrm{T} 2$, one $\mathrm{Cu}$ atom become single coordinated to the framework $\mathrm{O}$. On other $\mathrm{T}$ site pairs, both $\mathrm{Cu}$ atoms are double coordinated to framework $\mathrm{O}$, and bind stronger than the case on T1-T1 and T2-T2.

Table S1 List of relative stability of $\mathrm{Cu}-\mathrm{O}-\mathrm{Cu}$ on different $\mathrm{T}$ site pairs. Reference is $\mathrm{CuOCu}$ on T3-T3 sites.

\begin{tabular}{ll}
\hline $\begin{array}{l}\text { Sites host } \\
\mathrm{Cu}-\mathrm{O}-\mathrm{Cu}\end{array}$ & $\begin{array}{l}\text { Relative energy } \\
\left(\mathrm{kJ} \mathrm{mol}^{-1}\right)\end{array}$ \\
\hline T1-T4 & 18 \\
T1-T1 & 136 \\
T2-T2 & 56 \\
T2-T4 & 9 \\
T3-T3 & 0 \\
T4-T4 & 14 \\
\hline
\end{tabular}

\section{Steric hindrance of $\mathrm{CH}_{4}$ dissociation by T3-T3 site in 8MR}

The dissociation of $\mathrm{CH}_{4}$ is strongly endothermic by $149 \mathrm{~kJ} \mathrm{~mol}^{-1}$ on T3-T3 site in $8 \mathrm{MR}$, compared with the similar step on T1-T4 site in 12MR which is only slightly endothermic by $9 \mathrm{~kJ} \mathrm{~mol}^{-1}$ (Note that the final structure is $\mathrm{CH}_{3}$ attached to one $\mathrm{Cu}$ atom in both cases). The extra energy to dissociate $\mathrm{CH}_{4}$ on T3-T3 site is mainly due to the limited space in $8 \mathrm{MR}$. After $\mathrm{CH}_{4}$ dissociation, the symmetrically bi-coordinated $\mathrm{Cu}$ atoms $\left(d_{\mathrm{Cu}-\mathrm{O}}=201-204 \mathrm{pm}\right)$ become asymmetric, with one $\mathrm{Cu}-\mathrm{O}$ distance shorten to $195 \mathrm{pm}$ and the other one elongated 
to $235-245 \mathrm{pm}$ (Figure S2). It indicates that the $\mathrm{Cu}$ clusters start to detach away from framework, which is consistent with the weaker binding of $\mathrm{Cu}_{2} \mathrm{O}$ cluster after attachments of the dissociated fragments.

Besides in the $8 \mathrm{MR}$, the dissociated $\mathrm{CH}_{3}$ can also be located in the side pocket $8 \mathrm{MR}$ window. However, the orientation of $\mathrm{OH}$ group still points to $8 \mathrm{MR}$, leading less stabilization of the $\mathrm{OH}$ group to the $\mathrm{CH}_{3}$ radical. The enthalpy of this final structure is nearly identical $\left(+6 \mathrm{~kJ} \mathrm{~mol}^{-1}\right)$ to the one discussed above in $8 \mathrm{MR}$.

(a)

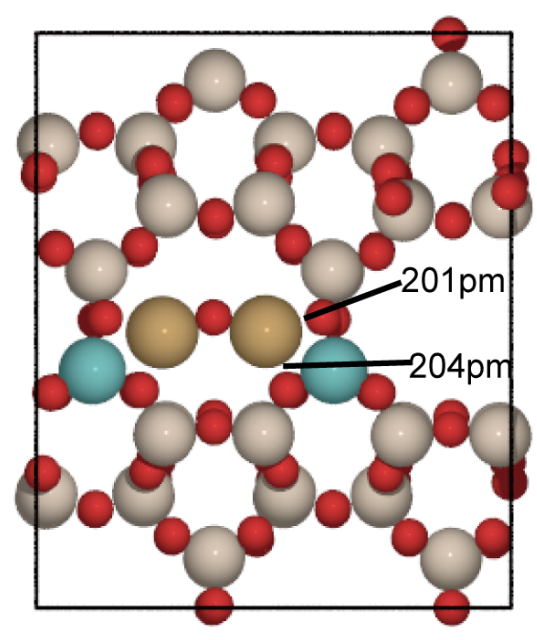

(b)

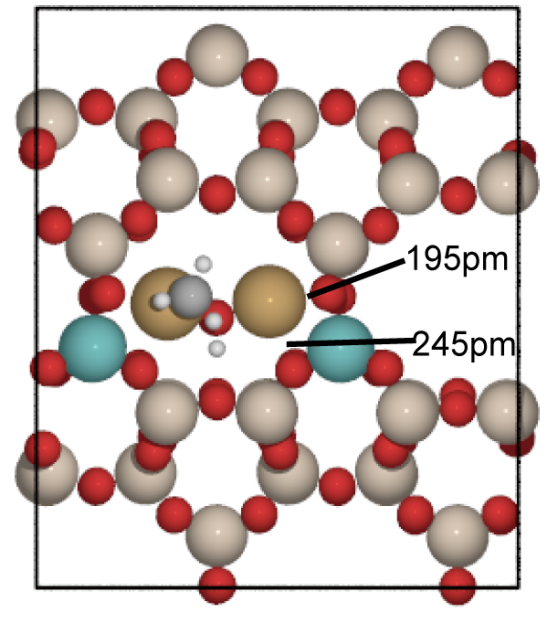

Figure S3 Structure of (a) $\mathrm{Cu}-\mathrm{O}-\mathrm{Cu}$ active site and (b) $\mathrm{Cu}-\mathrm{O}-\mathrm{Cu}$ active site after adsorbing $\mathrm{CH} 4$ dissociation fragment on T3-T3 site. 